\title{
SQUAMOUS CELL CARCINOMA AND NEUROENDOCRINE CARCINOMA COLLIDING IN THE ESOPHAGUS
}

\author{
doi: 10.1590/S1807-59322010000100018
}

André Roncon Dias, Rubens Antonio Aissar Sallum, Nathalia Zalc, Bruno Brito Ctenas, Ulysses Ribeiro Jr., Ivan Cecconello

\section{INTRODUCTION}

A collision tumor consists of two independent neoplasms growing in close proximity until they become juxtaposed, appearing as one lesion. This is a very rare situation with unclear physiopathology. Collision tumors should be distinguished from composite tumors, which consist of one neoplastic clone that diverges into two cell lineages. Collisions located in the esophagus are particularly uncommon.

\section{CASE REPORT}

A 51-year-old male patient, a former smoker and former alcoholic, presented with a glottic squamous cell carcinoma and underwent a total laringectomy with selective neck dissection (II, III, and IV). A pathological analysis of the surgical specimen confirmed a T2N0 squamous cell carcinoma, and adjuvant radiotherapy was performed (total dosage $6000 \mathrm{cGy}$ ). Six months later, the patient presented with progressive dysphagia, and an upper digestive endoscopy revealed an infiltrative tumor, approximately $2 \mathrm{~cm}$ long, in the distal esophagus. Biopsies revealed a poorly differentiated squamous cell carcinoma with areas of neuroendocrine differentiation. A Positron emission tomography scan demonstrated no extraesophageal disease.

The patient then underwent a subtotal esophagectomy with thoracic and abdominal lymphadenectomy (IvorLewis procedure). Reconstruction was performed with

Gastrointestinal Surgery Division, Hospital das Clinicas, Faculdade de Medicina da Universidade de São Paulo - São Paulo, Brazil.

Email: roncon86@ hotmail.com

Tel.: 55-11-4828-3353 an intrathoracic esophagogastric end-to-side mechanical anastomosis.

The surgical specimen revealed a lesion that was $2.5 \mathrm{~cm}$ wide, located $2 \mathrm{~cm}$ above the esophagogastric junction. Microscopy confirmed an in situ proliferation of squamous cells with abundant eosinophilic cytoplasm and high mitotic count with severe atypia in the nuclei. In very intimate contact with these squamous cells, there was another component of the tumor with a higher nuclei/ cytoplasm ratio, nuclei with a "salt and pepper" appearance and a very noticeably invasive behavior. Immunostaining of the tumor revealed that this second component exhibited neuroendocrine differentiation, being negative for $\mathrm{p} 63$ (the squamous component was p63-positive), strongly positive for Ki-67 (60\%), positive for synaptophysin and CD56, and focally positive for chromogranin A. The neuroendocrine component also exhibited a high mitotic rate (17 mitoses per 10 high power fields).

The interface between the two components of the tumor was abrupt. The squamous cell carcinoma was in situ, whereas the neuroendocrine carcinoma invaded the submucosal layer. Neural and vascular invasions were absent. The surgical margins were free, and there was no lymph node involvement ( $0 / 11$ dissected).

The postoperative course was uneventful, and the patient was discharged on the $12^{\text {th }}$ day after the procedure. He remains asymptomatic and disease-free after a follow-up of 26 months.

\section{DISCUSSION}

Collision tumors are rare lesions derived from two different histogenetic events. ${ }^{1}$ Two independent tumors grow in proximity until they become juxtaposed. They may be hard to differentiate from mixed or composite tumors, 


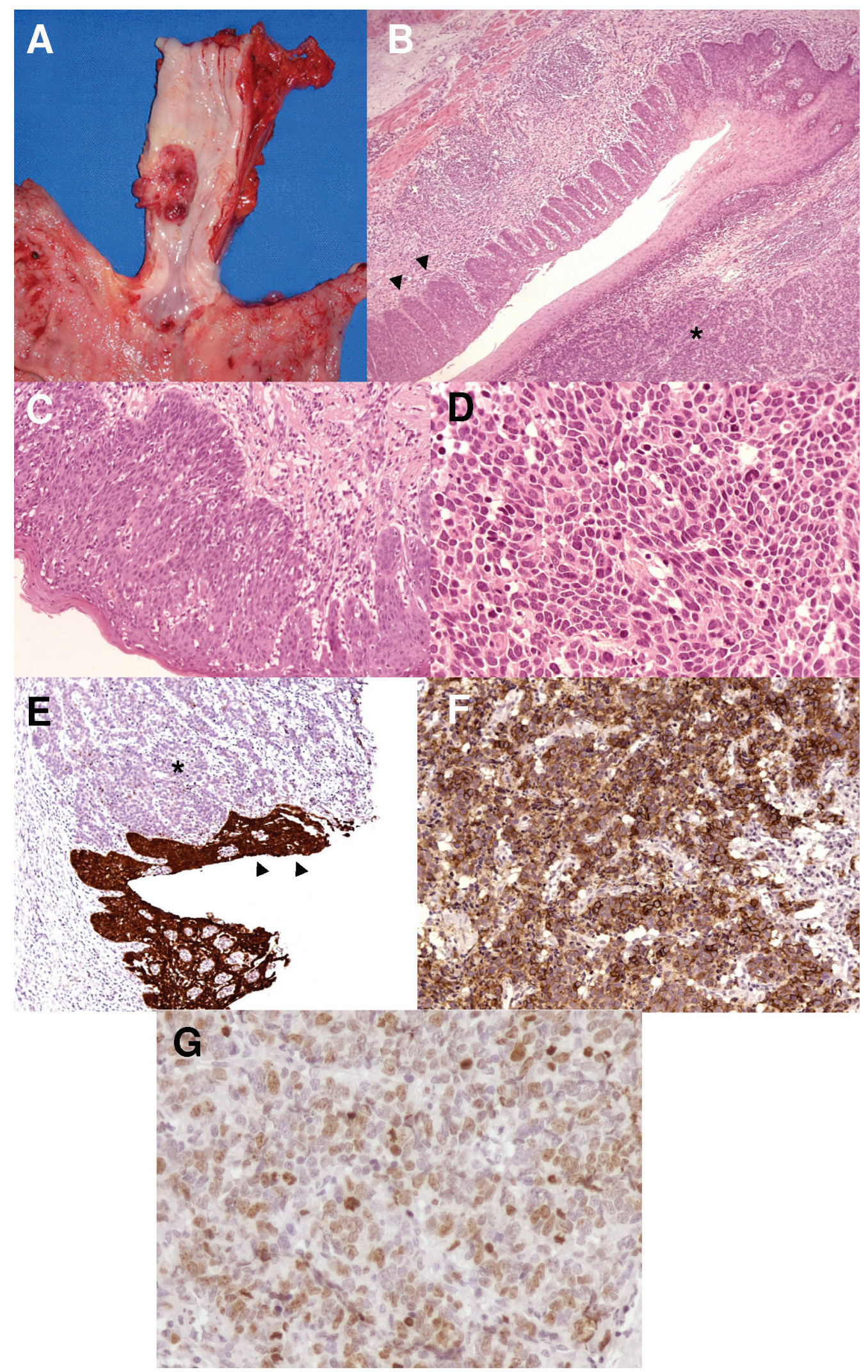

Panel: The exophytic ulcerated lesion in the distal esophagus (A) and its corresponding histopathology (B-E). B - Low-magnification image showing the squamous "in situ" component (arrowheads) and the neuroendocrine, nest-arranged component (asterisks). C - High-magnification image of the squamous cell component. D - High-magnification image of the neuroendocrine component with typical "salt and pepper" nuclei. E - Cheratin immunostaining showing the squamous component (positive in brown - arrowheads) and the neuroendocrine component (negative - asterisks). F - High-magnification image of a CD56-positive neuroendocrine area. G - High-magnification image showing Ki-67 positiveness. 
when one mutated cell diverges into two clones resulting in two different neoplasms. ${ }^{1-3}$ Histopathological analysis, immunohistochemical analysis, microsatellite instability research and electron microscopy can all help distinguish between these two situations.

In the present case, the microscopic findings demonstrated an abrupt transition between the two components, this is expected for collision tumors, differing them from composite tumors in which the two components intermingle. The immunohistochemical analysis revealed a pattern compatible with a neuroendocrine component located next to the squamous "in situ" component.

The physiopathology of collision tumors is still unclear, but recent data suggest that the proposed accidental meeting of two independent tumors is not in accord with what is known today about carcinogenesis. The field effect of carcinogens probably plays a major etiological role in the process, and the present patient is a good example of this. Mucosal exposure to alcohol and smoke probably initiated various cells in his respiratory and upper digestive tracts, allowing further mutations to originate two squamous cell carcinomas (glottic and esophageal). ${ }^{7}$

It is also known that a neoplasm's surrounding area is altered, influencing cancer growth and contributing to epithelial instability. ${ }^{8-10}$ Therefore, it is plausible that a pool of initiated cells in an area may be stimulated by an altered microenvironment, ultimately resulting in a second neoplasm that can grow until it collides with the first tumor. Although knowing which component appeared first in this case is impossible, it is probable that the first neoplasm contributed to the rise and growth of the second.

With respect to the risk factors for neuroendocrine tumors, their occurrence is mainly attributed to genetic alterations. ${ }^{11}$ According to the most recent World Health Organization classification, neuroendocrine tumors can be separated into three main categories with distinguished histology and prognosis: well-differentiated neuroendocrine tumors have a low malignant potential, well-differentiated neuroendocrine carcinomas are more aggressive lesions with metastatic potential, and poorly differentiated neuroendocrine carcinomas are high grade malignancies with poor prognosis. ${ }^{12}$ The present case was classified as a well-differentiated neuroendocrine carcinoma.

With regard to prognosis, for in situ squamous cell carcinomas a five-year survival rate greater than $85 \%$ can be expected. ${ }^{13}$ There is no specific staging system for neuroendocrine carcinomas, and some authors prefer not to use the TNM system (International Union Against Cancer), instead relying on the framework recommended by the Veterans Administration Lung Study Group, which classifies lesions into two categories: limited disease (tumor contained within a localized anatomic region, independent of regional lymphatic involvement) and extensive disease (tumor outside locoregional boundaries). Treatment for the limited disease is potentially curative, and surgery represents the best chance for a cure. ${ }^{14}$ Also, the best predictor of survival for neuroendocrine tumor cases seems to be the Ki-67 score and not the degree of differentiation or the tumor site, as expected. $^{12}$

It should be also noted that the esophageal lesion was probably present at the time of the first operation. Although it was not diagnosed at that time, this situation underscores the importance of a full investigation of the airways and upper digestive tract in patients with squamous cell carcinoma in one of these tracts. The assessment should include an upper digestive endoscopy with chromoscopy.

As for the surgical choice, a cervical approach was not considered since the patient had severe surgical and actinic alterations in this region.

Esophageal collisions are particularly uncommon and usually occur in association with Barrett's esophagus. ${ }^{4-6}$ To our knowledge, this is the first report of an esophageal collision between a squamous cell carcinoma and a neuroendocrine carcinoma.

\section{REFERENCES}

1. Pecorella I, Memeo L, Ciardi A, Rotterdam H. An unusual case of colonic mixed adenoendocrine carcinoma: collision versus composite tumor. A case report and review of the literature.Ann Diagn Pathol. 2007;11:285-90.

2. Lewin K. Carcinoid tumors and the mixed (composite) glandularendocrine cell carcinomas.Am J Surg Pathol. 1987;11 Suppl 1:71-86.

3. Fenoglio-Preiser CM. Carcinomas and other epithelial and neuroendocrine tumors of the large intestine. In: Fenoglio-Preiser, editor. Gastrointestinal pathology. An atlas and text. $2^{\text {nd }}$ edition. Philadelphia: Lippincott-Raven; 1999. p.909-10.
4. Slaughter DP, Southwick HW, Smejkal W. Field cancerization in oral stratified squamous epithelium; clinical implications of multicentric origin. Cancer. 1953;6:963-8.

5. Schwartz L, Balosso J, Baillet F, Brun B, Amman JP, Sasco AJ. Cancer: the role of extracellular disease.Med Hypotheses. 2002 ;58:340-6.

6. Mueller MM, Fusenig NE. Friends or foes - bipolar effects of the tumour stroma in cancer. Nat Rev Cancer. 2004;4:839-49.

7. Ishiguro K. Yoshida T, Yagishita H, Numata Y, Okayasu T. Epithelial and stromal genetic instability contribuyes to genesis of colorectal adenomas. Gut. 2006;55;695-702. 
8. Hassan MM, Phan A, Li D, Dagohoy CG, Leary C, Yao JC. Risk factors associated with neuroendocrine tumors: A U.S.-based case-control study. Int J Cancer. 2008. 15;123:867-73.

9. Naritaka Y, Ogawa K, Shimakawa T, Wagatsuma Y, Isohata N, Asaka S, et al. Collision carcinoma of the residual cervical esophagus 27 years after esophageal cancer surgery. Anticancer Res. 2007;27:505-11.

10. González LM, Sanz-Esponera J, Saez C, Alvarez T, Sierra E, SanzOrtega J. Case report: esophageal collision tumor (oat cell carcinoma and adenocarcinoma) in Barrett's esophagus: immunohistochemical, electron microscopy and LOH analysis. Histol Histopathol. 2003;18:1-5.

11. Wilson CI, Summerall J, Willis I, Lubin J, Inchausti BC. Esophageal collision tumor (Large cell neuroendocrine carcinoma and papillary carcinoma) arising in a Barrett esophagus.Arch Pathol Lab Med. 2000;124:411-5.
12. Faggiano A, Mansueto G, Ferolla P, Milone F, del Basso de Caro ML, et al. Diagnostic and prognostic implications of the World Health Organization classification of neuroendocrine tumors. J Endocrinol Invest. 2008;31:216-23.

13. Sabik JF, Rice TW, Goldblum JR, Koka A, Kirby TJ, Medendorp SV, Adelstein DJ. Superficial esophageal carcinoma. Ann Thorac Surg. 1995;60:896-901.

14. Lin TY, Chao YC, Cheng MF, Lee HS, Chang WK. Primary Neuroendocrine Carcinoma of the Esophagus. J Med Sci. 2007;27:77-80. 